
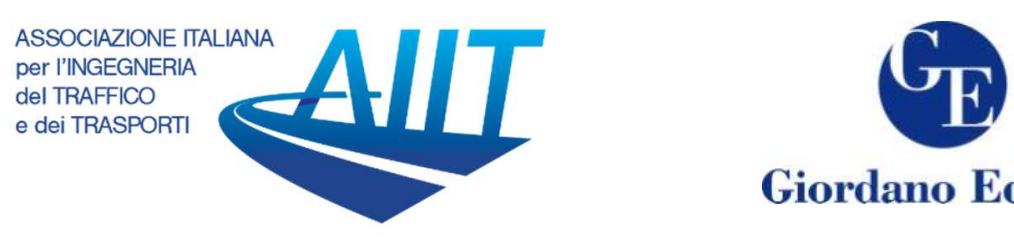

Giordano Editore

\title{
Analysis of European land transport network, MEGAs and socio-economic setting through Territorial Frames model
}

\author{
Donato Di Ludovico", ${ }^{1,2 *}$, Benedetta Di Giacobbe ${ }^{1,2}$, Gino D'Ovidio ${ }^{1,2}$ \\ ${ }^{1}$ Department of Civil, Construction-Architectural and Environmental Engineering, University of \\ L'Aquila, 67100 L'Aquila, Italy \\ ${ }^{2}$ CITRAMS - Sustainable Transport and Mobility Research Centre, University of L'Aquila
}

\begin{abstract}
The paper illustrates an innovative method, Territorial Frames (TFs) model based, to analyse in the European context the relation among the spatial distribution of the main urban and productive agglomerations (MEGA), the territorial socio-economic setting and the endowment and performance features of the land transport network.

The proposed model allows the spatial context to be divided into a multi-scalar sum of TFs, conceived and designed as parts of the territory, with homogeneous spatial and socio-economic characteristics, delimited by multimodal transportation corridors.

The assumptions for model construction is illustrated and the final European TFs (ETFs) spatial outline is proposed. In addition, through the introduction of appropriate indices, for each ETF several analyses of correlation between the socio-economic and transport network endowment/features aspects have been carried out. The results, illustrated and discussed both in numerical and spatial terms, show a close correlation between the above aspects.
\end{abstract}

Keywords: regional development, railway and roadway networks, performance transport network analysis, transport geography, spatial planning.

\section{Introduction}

This paper deals with some issues related to the interpretation of transport geographies with a cross-scale approach (Di Ludovico, D'Ascanio, 2019), from the territorial to the local level. The model that derives from this approach, which we have defined Territorial Frames - TFS, can be considered a support structure for new development processes of the European space and its territories (Raines, Goodwin, Cutts, 2017).

The settlement system, which represents the base and the fabric on which the TFs are structured and on which they operate, is interpreted by European planning through the Polycentric model (ESPON, 2005), to which the outdated European Spatial Development Perspective - ESDP refers, which however remains the only EU approach to spatial

\footnotetext{
*Corresponding author: Donato Di Ludovico (donato.diludovico@univaq.it)
} 
planning in the European region, (Faludi, 2010a; Faludi, 2010b; Williams, 1996) which intervenes on the development of the territory. The polycentric model (Shaw, Sykes, 2004; Davoudi, 2003) is used as an analytical tool to explain the urban growth models of geographers and urban planners from the 1960s onwards (Rauhut, 2016), and it is introduced in the ESDP with the aim of pursuing a development of a balanced and polycentric urban system and a new urban-rural relationship. It is also taken up in subsequent EC documents related to the new European programming.

Our TFs model uses the polycentric system as the reading reference of the settlement system and, as will be seen later, its definition of the configuration of the major European cities which we consider the main nodes for identifying TFs. The current major European cities are the result of transformations relating to numerous historical periods up to the post-industrial period (Carmona et al., 2003; Choay, 1992) and a UN study has calculated that from 2014 to 2050 the world population in urban areas will increase from $54 \%$ to $66 \%$ (UN-DESA, 2014).

The main objective of our research is therefore to combine a new interpretative geography of the transport system with evolving European polycentric geography, to obtain a model, from which the TFs, to support cross-scale spatial development, a process defined Glocalization (Robertson, 1992; Bauman, 1998). This methodology tries to overcome some gaps inferable from the scientific literature:

- The polycentric model doesn't seem to address sufficiently the issues of resource balance and equity development (Waterhout, 2002; Hall, 2001; Rauhut, 2016; Van Meeteren et al., 2015; Shaw, Sykes, 2004), in the scenario of continuous growth of metropolitan areas and weakening of the most critical ones, the local contexts/crisis areas (Noguera et al., 2017), which are issues that recall the centrality of territorial planning (Faludi, 2010a).

- The models proposed by the scientific literature on transport geographies are essentially based on econometric approaches referring to consolidated or innovative methodologies that do not consider the link, and therefore integration, with the territorial and spatial components and especially with the development of the latter, that we place at the heart of our TFs model. The existing models are "linked to tour frequency, mode and destination choice" and are related to the analysis of "O/D rail passenger and car driver trip matrices" (Lundqvist, Mattsson, 2002). Even the most innovative models focus on travel and traffic modelling and on the transport demand (Bernardino et al., 2015; Lundqvist, Mattsson, 2002), freight and market (Saeedi et al., 2017), cost-benefit analysis (Jones, Moura, Domingos, 2014). For instance, the integrated TRIMODE model, studied in Europe, combines the simulation of transport, economy and energy systems for the assessment of major projects and transport infrastructure policies (Fiorello, Nökel, Martino, 2018), or the TRANUS model, which simulates the "probable effects of projects and policies of different kinds in cities and regions", and "evaluate the effects from economic, financial and environmental points of view" (Tranus, 2011).

In response to these gaps, our research therefore proposes an original spatial and transport interpretative model, the TFs (Di Ludovico, D'Ascanio, 2019; Di Ludovico, D'Ovidio, 2017; Di Ludovico, Properzi, Santarelli, 2014), with particular reference to transport/territorial methodological criteria, a cross-scale infrastructural network based on the polycentric network of cities. TFs are designed as parts of the territory, with peculiar characteristics, delimited by multi-modal transportation branches having different degrees of completeness. 
The TFs model is conceived and designed as a spatial planning support tool that pursues the improvement of the performance of settlement and mobility systems. As we will see in the paper, within the TFs we will prepare some analyses on the territorial, environmental and landscape components, which will allow us to produce original interpretations of the dynamics of the European space, interpretations that imply that the structure of the TFs (i.e. the structure of transport) is integrated with the underlying systems (territorial, environmental and landscape). This approach, in an evolution of research, can be used to implement such integration through coordinated and co-planned territorial strategic projects (Albrechts, 2006) governed through new forms of partnerships and networks, new 'regional' aggregations, the Spatial rescaling (Allmendinger, Haughton, 2009) within the TFs and innovative technologies for high speed transport systems (D'Ovidio, Crisi, Lanzara, 2011; D’Ovidio et al, 2007).

This paper refers to the definition of the criteria for the identification of the European TFs mesh and its application to the European spatial context. The definition will be based on some cornerstones, such as the planning lines dictated by the EU (ESPON, 2005), the Ten-T network and the European corridors (EC, 2017), or those proposed by Espon as in the last "Making Europe Open and Polycentric, Vision and Scenarios for the European Territory towards 2050 ".

Section 2 of the paper presents the TFs model definition, in relation to cities and land infrastructural networks. The application of TFs model on the European context is illustrated and discussed in Section 3. Section 4 shows a series of thematic analyses on the study context using infrastructural and socio-economic indicators through TFs model. The concluding remarks are in Sections 5 and 6.

\section{TFs model construction criteria}

TFs can be conceived as spatial meshes whose sides are made up of the main single/multimodal transport corridors (branches), characterised by their completeness/incompleteness, on which flows of goods and people move and whose nodes are the main urban and productive agglomerations.

In general terms, the formal components of TFs are identified as follows:

- Branches, drawn on the route of the mono/multimodal land transport infrastructures;

- Nodes, coinciding with the most important urban agglomerations;

- Hubs important branches intersections.

Below are the criteria for the univocal construction of the TFs model:

(i) The minimum structure of a frame is composed of three branches and three nodes.

(ii) The Frames design must always be reduced to its minimum structure. Where this is not possible, the layout may meet other nodes and/or hubs, while still respecting the condition of reduction to the minimum achievable shape.

(iii) In order to close a TF, a hub can be considered as a node, in compliance with the previous criteria.

(iv) The flow hierarchy is used as a discriminating element to identify the preferred TFs configuration in case of alternative configurations. In this case, the TFs branch subject to greater traffic flow is chosen.

The model has a cross-scale application, since it can be used at different levels of observation: European (ETFs), national, (NTFs) and local (LTFs) contexts (Di Ludovico, D'Ascanio, 2019). These TFs systems are overlapping and integrated meshes that determine a fine fabric TFs + City Networks (Di Ludovico, Properzi, 2012) capable of connecting the local to the global (Brenner, 1999; Bauman, 1998; Robertson, 1992). 
At each scale, the TFs model allows to carry out different sets of transport and socioeconomic analyses. The results of these analyses allows to relate the level of integration of land infrastructure network (on which the TFs are built) to the socio-economic conditions of the territories. The TFs model therefore represents an interpretative model of all contexts.

\section{Application of the method to the European context}

In this paper, the TFs method has been used to analyse the European context in order to perform transport and socio-economic analyses. The selected study context concerns the European territorial configuration E-28, extended to Switzerland, Norway and the Balkan area.

The analyses have been performed by using European data relating to the NUTS3 administrative level, 1470 sub-regional units with a total of 545,069,397 inhabitants. NUTS level 3 are territorial units corresponding to the Italian provinces, the Nomoi in Greece, the Maakunnat in Finland, the Län in Sweden, the German Kreise, the French departments, the Spanish provinces, the Croatian counties, etc.

The choice to use data referring to the NUTS3 administrative level derives from two considerations: the actual availability of these data from the main statistical sources, and the need to discretise the European territory as much as possible in order to have a more detailed basis and to measure all frame sizes, even the smallest ones.

The selected context is analysed by using the TFs model with the aim of defining a new system of spatial interpretation and carrying out cross-scale analyses of settlement, environmental, landscape, economic and infrastructural type.

At the European scale, the main components of TFs are identified as follows:

1. Branches defined as multimodal corridors where there is the co-presence of the main road (motorways and expressways) (Fig. 2) and the electrified railway links (Fig. 3).

2. Hubs, main intersections of the branches.

3. Nodes, coinciding with the MEGAs (ESPON, 2005), defined as major European metropolitan areas of growth. More in detail, MEGAs are defined as the 76 largest European Functional Urban Areas in terms of:

- Mass. The denser a region's economic environment is, the more likely it is to present favourable conditions for its development. Mass is measured by the population size and the size of the economy.

- Competitiveness. The degree of attractiveness for private companies is measured by the Gross Domestic Product (GDP) per capita and the location of head offices for the top 500 European companies.

- Connectivity. Attractive regions have good connectivity to other regions. Indicators used here are the number of airport passengers and the regions' multimodal accessibility.

- Knowledge basis. The percentage of the population with higher education and the share of the employed working with R\&D measure the attractiveness of a FUA.

Taking into consideration these characteristics, MEGAs have been divided into: 2 Global Cities, 17 European Engines, 8 Strong MEGAs, 26 Potential MEGAs, and 23 Weak MEGAs.

Fig. 1 shows the partition of the European territory by NUTS 3, illustrates the geographical distribution of the MEGA and their classification. 
Fig. 2 illustrates the distribution of MEGAs in relation to the European main road network (motorways and expressways) with the indication of the branch flow in terms of Annual Average Daily Traffic (AADT).

Fig. 3 shows the distribution of MEGA in relation to the European railway network with an indication of the flow loads (trains/year) for each branch.

The co-presence of main road and rail transport in the same infrastructure section determines the identification of the frame branch, between two nodes or between a node and a hub.

The outlined configuration of the ETFs comes from a unique reproducible method. It can be adapted to the evolution of the MEGAs system (ESPON, 2005) and the transport infrastructure network over time (EC, 2017).

Once the components, i.e. nodes, potential branches and hubs, have been identified, the assumptions guide the outline of the ETFs in the study context, as shown in Fig. 4. A system of 35 ETFs has been identified. It can be noted that there are some areas that are not covered by the TFs, such as Southern Italy, the Balkan area, North-Western France, Ireland, the Baltic States and the Scandinavian peninsula. This circumstance clearly highlights a lack in efficient transport and settlement systems.

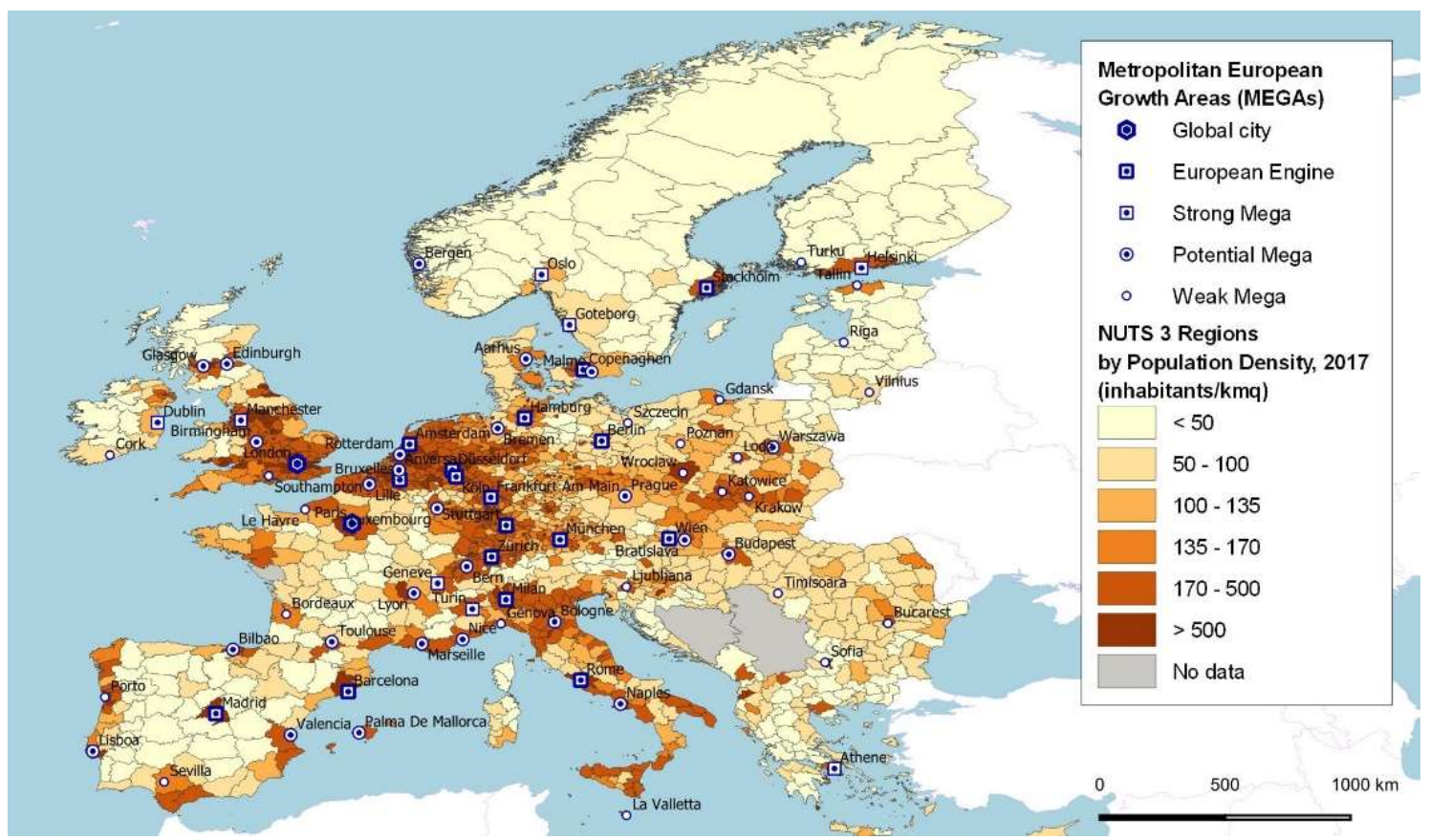

Fig. 1: NUTS 3 Regions by population density and MEGAs.

Source: https://ec.europa.eu/eurostat/web/products-datasets/product?code=demo_r_d3dens; ESPON, 2005. 


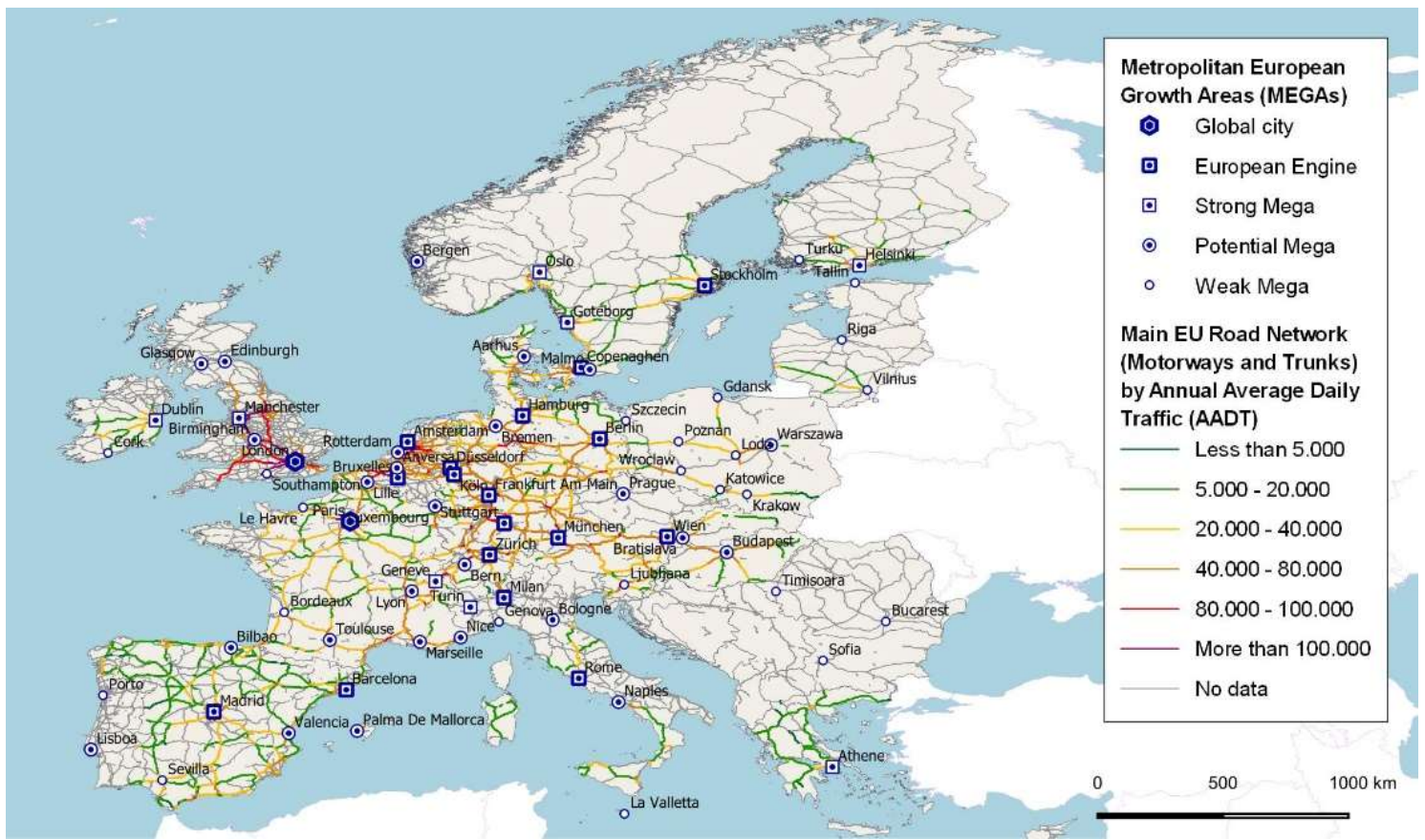

Fig. 2: European Main Road Network and Annual Average Daily Traffic - AADT. Source: https://www.openstreetmap.org/; http://web-gis.cedr.eu:8082/cedr/index_cedr.php; https://www.unece.org/trans/main/wp6/e-roads_maps.html; ESPON, 2005.

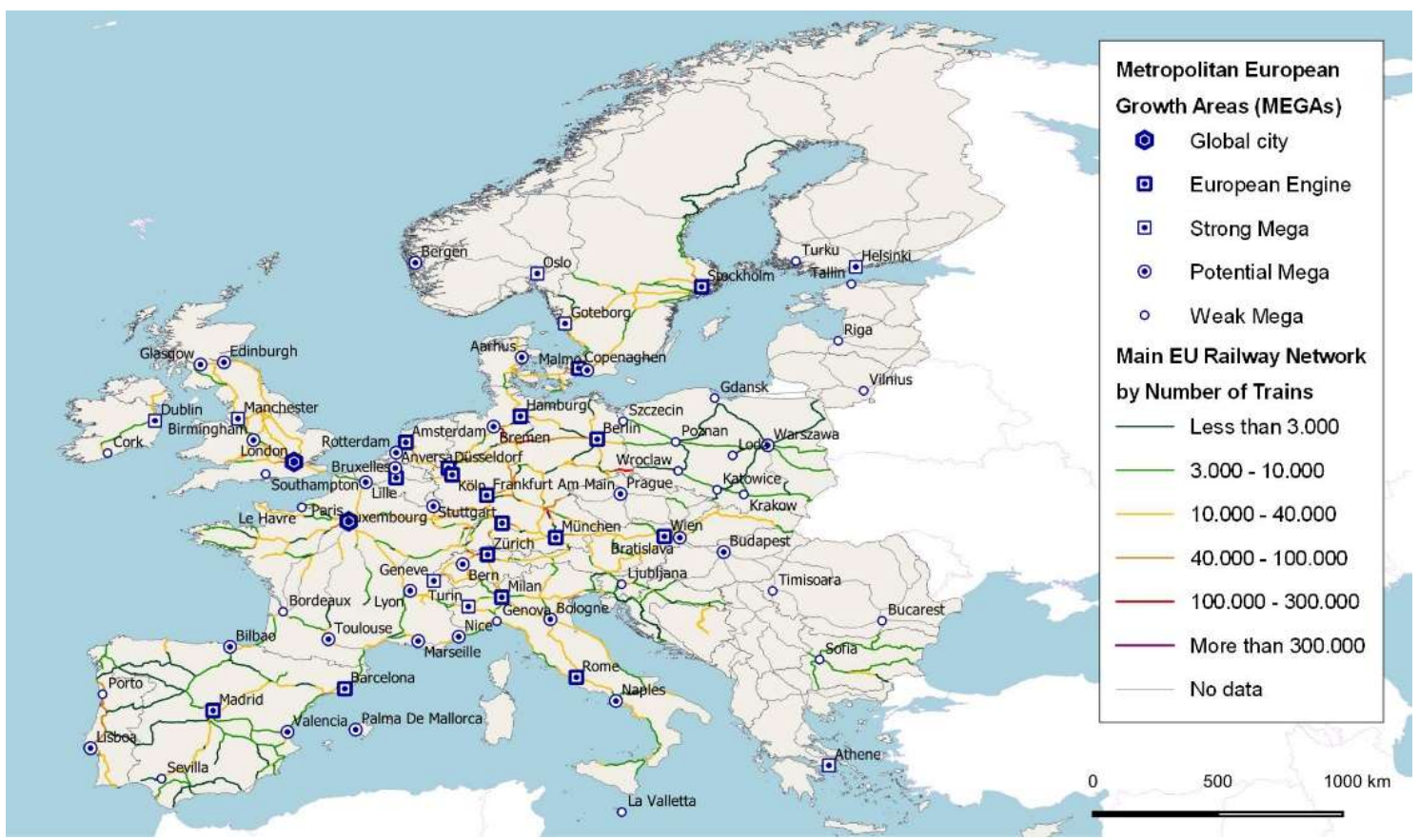

Fig. 3: European Main Railway Network and Annual Number of Trains.

Source: UNECE, 2017; https://www.unece.org/trans/areas-of-work/transport-statistics/statistics-and-dataonline/e-rail-census/traffic-census-map.html; ESPON, 2005. 


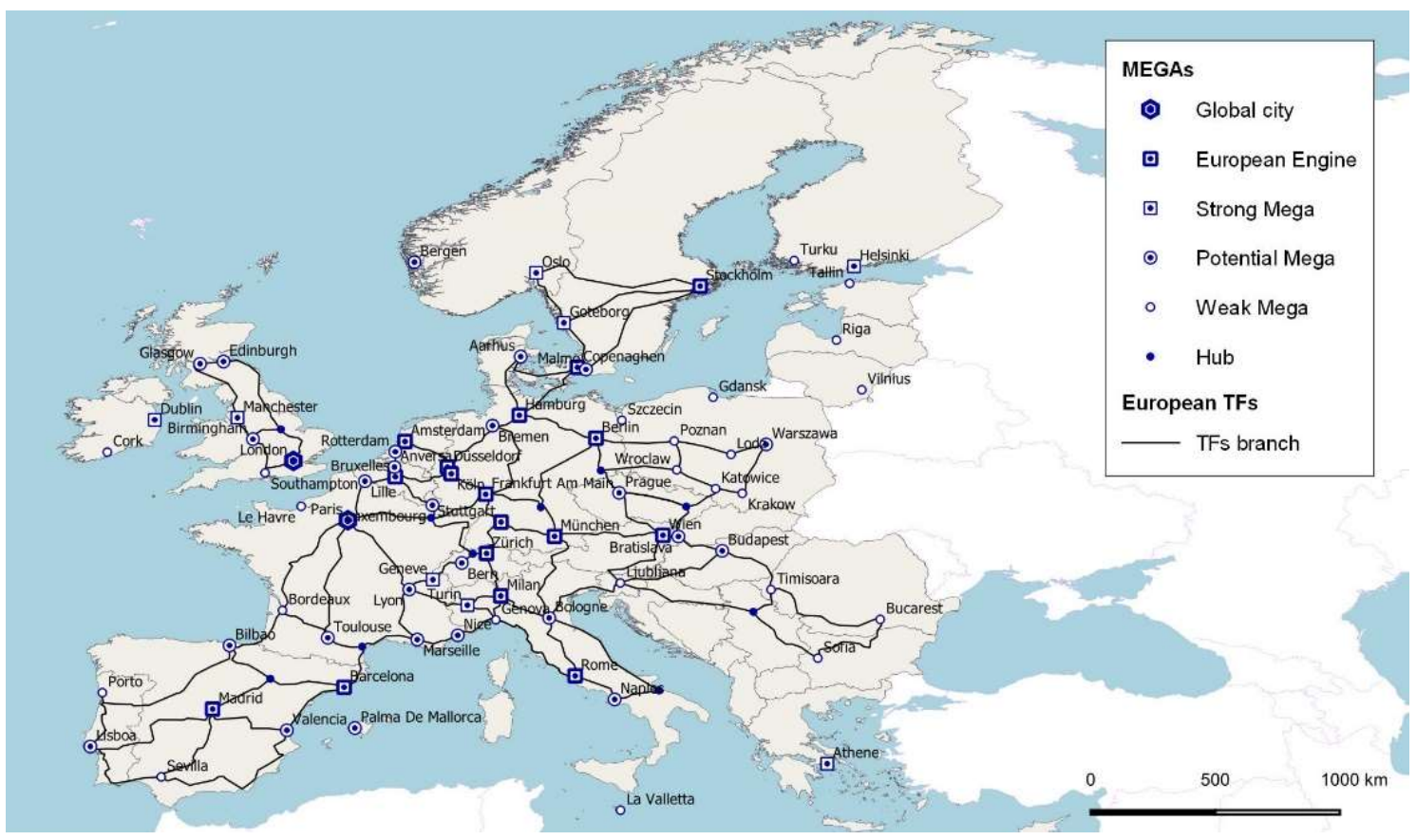

Fig. 4: European Territorial Frames (ETFs) with indication of nodes (MEGAs), branches (multimodal corridors) and hubs.

\section{Application of the method to the European context}

For each ETFs, the application of the proposed method made it possible to carry out multiple analyses concerning transport infrastructure endowment/features and Socioeconomic setting.

The analyses aim at characterizing the territorial study context through the ETFs model, with the intention of correlating the characteristics of the land transport system with the socio-economic development conditions of the territories, but also with their environmental and landscape characteristics.

The method considers the NUTS3 regions included in each TF and the ones crossed by the branches.

\subsection{Transport analysis.}

The first group of ETFs-based analyses concerns the transport sector. Three indices will be described in the next sub-sections.

\subsubsection{Optimization Indices}

The optimisation indices concern the transport characteristics of both the individual ETF branch and all the branches belonging to the same ETF.

The Branch Optimisation Index $\left(I_{O b}\right)$ assesses, by means a numerical value, whether the branches belong or not, to:

- The High-speed $(>200 \mathrm{~km} / \mathrm{h})$ railway network completed or nearing completion (UNECE, 2017).

- The Land Trans-European TEN-T network; it is part of the European Commission's programme with the overall objective of establishing a single multimodal transEuropean network consisting of a system of 9 crossing corridors (EC, 2017). 


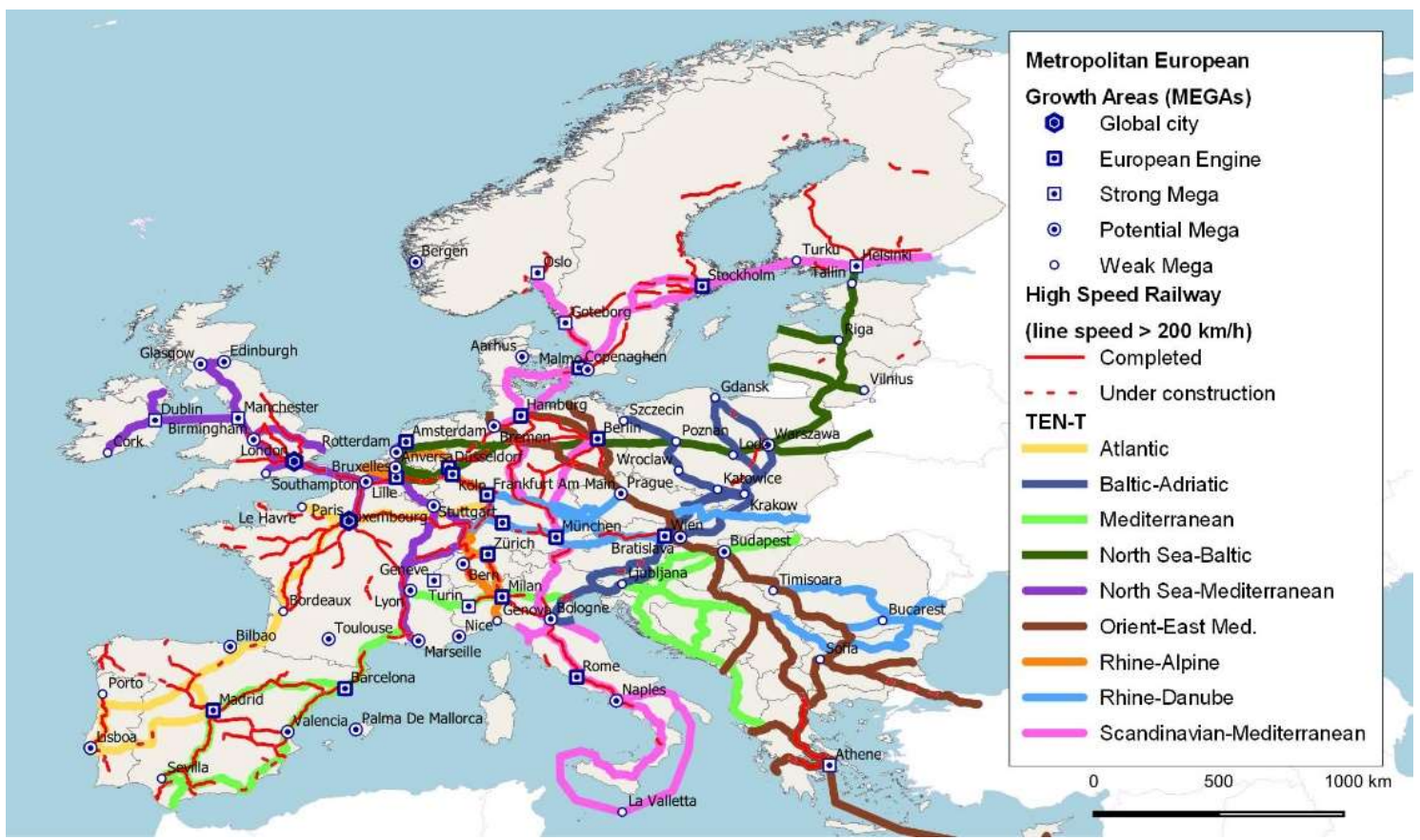

Fig. 5: High Speed Railway and Trans-European Network Transport Corridors.

Source: UNECE, 2017; ESPON, 2005.

In accordance with the above, for each ETF branch, the $I_{O b}$ assumes the following values:

0.0 Not belonging to either network

0.5 Belonging to a High Speed railway (in completion/planned)

1.0 Belonging to a High Speed railway or to a Transnational European TEN-T transport network

1.5 Belonging both to a High Speed railway in completion/planning and TEN-T network

2.0 Belonging both to a High Speed railway and a TEN-T network

Therefore, the high values of $I_{O b}$ indicate simultaneously, for a given ETF branch, higher performance characteristics of the rail system in terms of speed and a higher degree of connection as part of the preferential transport corridors.

Moreover, in order to define the transport characteristics of the entire frame (all branches of the ETF), the ETF Optimization Index IOf has been introduced and calculated using the relation (1).

$$
I_{o f i}=\frac{\left(\sum_{j=1}^{N b i} I_{o b j}\right)_{i}}{N_{b i}}
$$

where: Iofi is the i-th frame optimization index; $N_{b i}$ is the number of branches of the i-th frame and $I_{O b j}$ is the j-th branch optimization index, with $j=1, \ldots, N_{b}$.

The value of $I_{O f}$ ranges between 0 (no degree of optimization) and 2 (maximum degree of optimization, in the condition in which all the TFs branches have the maximum degree of optimization).

Figure 6 illustrates, for each ETF, the values of $I_{O b}$ (reffering to the single branch) and $I_{O f}$ (referring to the ETF as a whole), respectively. The results show that the ETFs with the highest $I_{O f}$ values are located in the regions of central-northern Europe, with the 
exception of the one located in the region of Catalonia. On the contrary, the peripheral ETFs have lower $I_{O f}$ values.

Consequently, in general terms, it can be said that the regions of central-northern Europe, compared to the more peripheral ones, are characterised by more efficient and more integrated land transport links.

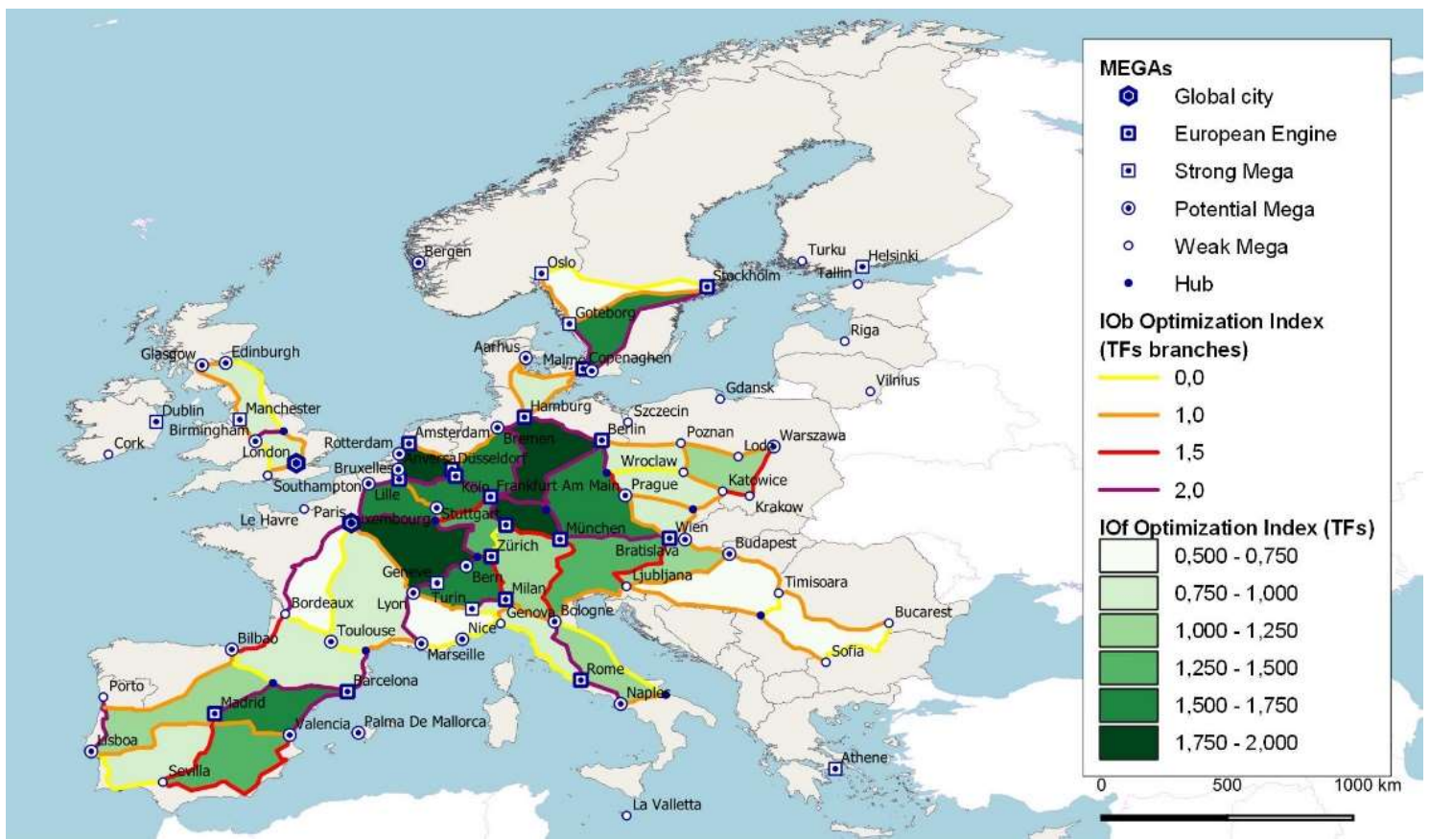

Fig. 6: Branch Optimization Index $I_{O b}$ and ETFs Optimization Index $I_{O f}$

\subsubsection{Sub-Network Index}

The Sub-Network Index $I_{S}$ concerns the density evaluation of the ETF internal transport infrastructure endowment. It is defined as the ratio between the extension of the multimodal land transport network (road and rail) inside the ETF and ETF area extension (sources in Fig. 7). In other words, the $I_{s}$ indicates, for each ETF, the density of the transport infrastructure endowment.

Fig. 7 illustrates, for each ETF, the values of the $I_{S}$ index. The results show that northern TFs, in particular those belonging to England, Belgium, Netherlands and northern Germany, up to northern Italy have highest values density of $I_{s}$. 


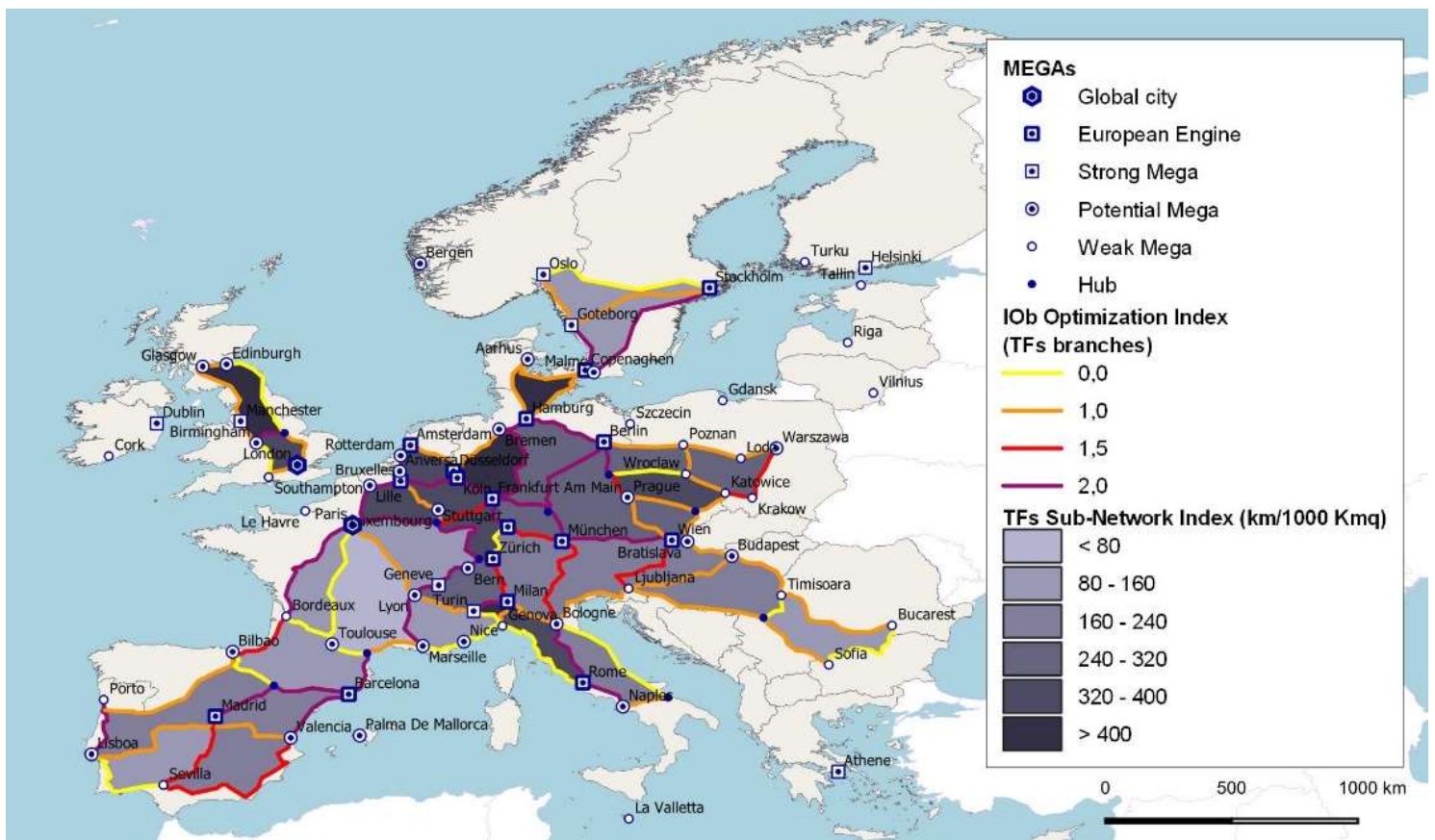

Fig. 7: ETFs Sub-Network Index $I_{s}$ and $I_{O b}$ Optimization Index.

\subsubsection{Daily Accessibility Index}

The Daily Accessibility Index $I_{a}$ is based on the evaluation of the ETF internal transport infrastructure (sub-network) time performance. The $I_{a}$ indicates, for each ETF, the functionality and performance of the transport sub-network in terms of daily accessibility, defined as the amount of people that live within four hours of driving from the location at hand. Fig. 8 illustrates, for each ETF, the values of $I_{a}$, measured in millions of people per day. ETFs in the regions of Northern Germany, Belgium and southern England have higher $I_{a}$ values.

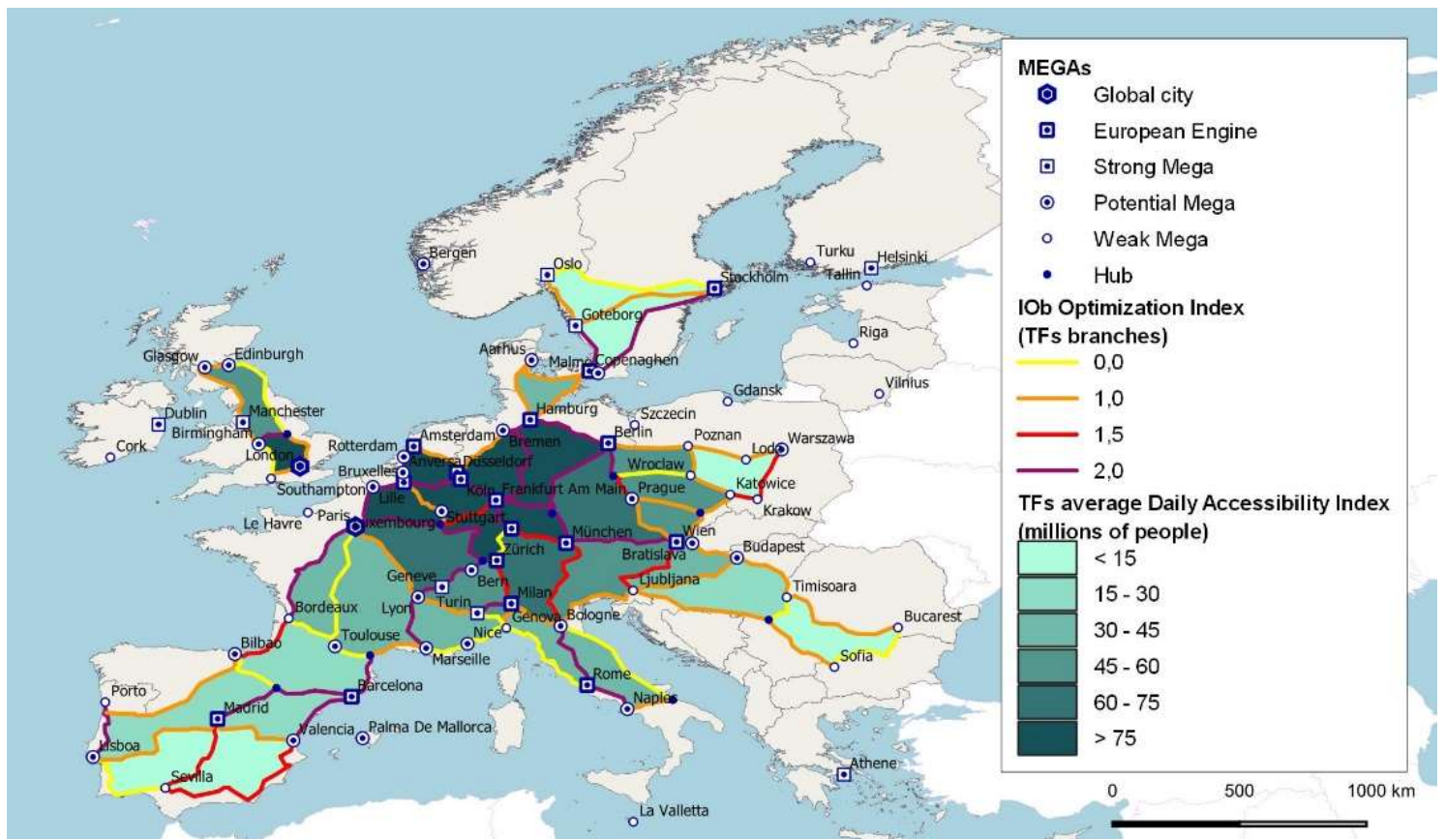

Fig. 8. ETFs Daily Accessibility Index $I_{a}$ and $I_{O b}$ Index 


\subsection{Socio-economic analyses}

Alongside the first group of ETFs-based analyses concerning the transport sector, a second group of Socio-economic analyses has been carried out by using regional Eurostat NUTS3 data. The purpose of these analyses is to identify, for each ETF, two indices: (i) Gross Domestic Product Index and (ii) Employment Rate Index. These indices are related to the transport type indices, calculated in the sections above. This can be read in the figures in the form of overlap with the Optimization Index (ETFs branches), which will be described in the results section.

\subsubsection{Gross Domestic Product Index}

The GDP Index $I_{g}$ describes the ETF's average GDP calculated as percentage of the EU-28 GDP average.

Fig. 9 shows the overlapping between the values of the $I_{O b}$ index and $I_{g}$ index. Once again, we note that the ETFs with the highest $I_{g}$ index are those relating to the regions of central-northern Europe.

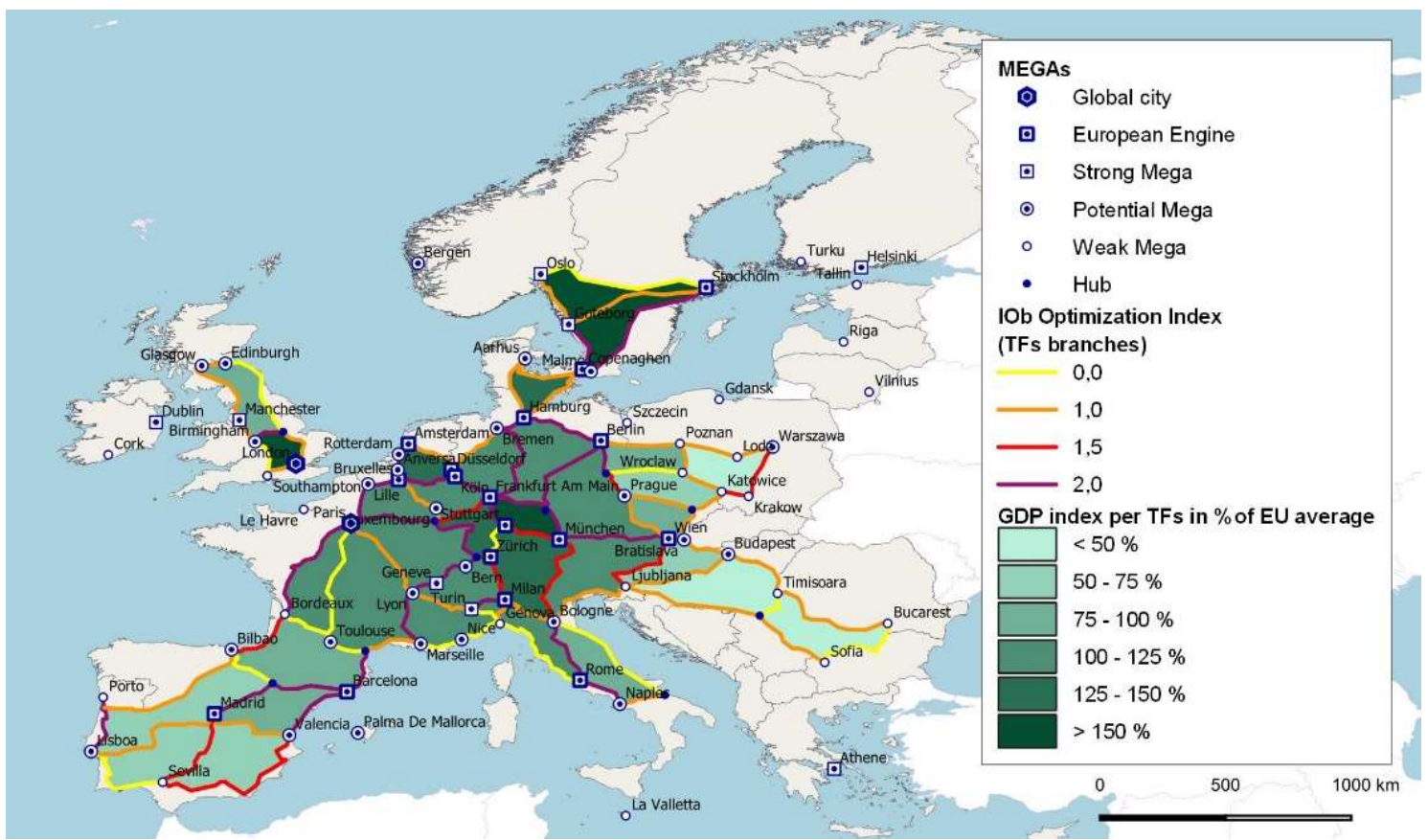

Fig. 9: ETFs Ig index and $I_{o b}$ index.

\subsubsection{Employment Rate Index}

The second socio-economic Employment Rate Index $I_{e}$ is introduced in order to evaluate, for each ETFs, the employment rate of the population (on Eurostat data). The $I_{e}$ is defined as the ratio between the employed population and the working-age population (15-64 years old).

Figure 10 shows the overlapping of the values of $I_{O b}$ index and the $I_{e}$ index. We note that the highest $I_{e}$ values characterizes the ETFs of the central-northern regions of Germany, the Scandinavian regions and the London area. 


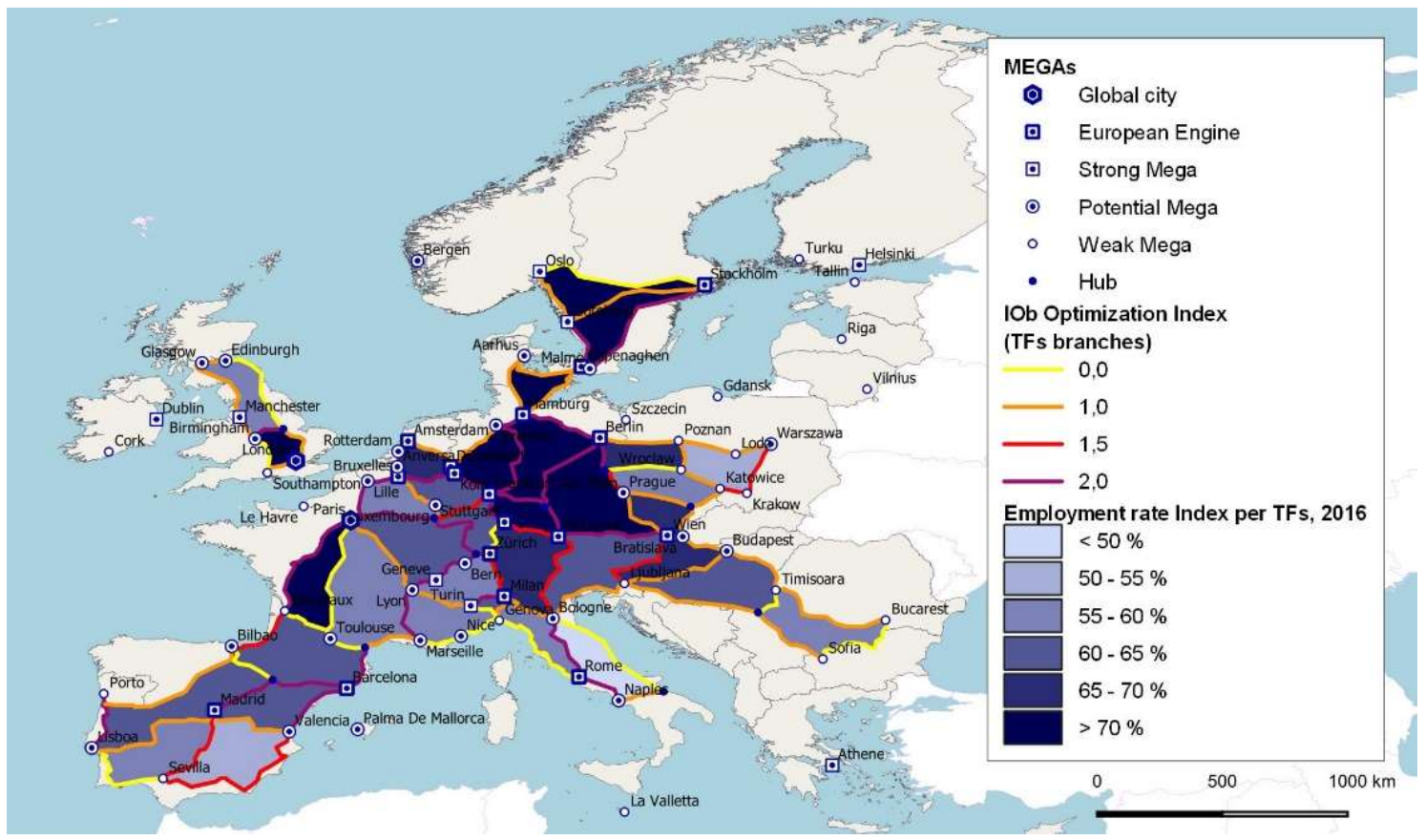

Fig. 10: TFs Employment rate $I_{e}$ Index and $I_{O b}$ Index.

\section{Results}

As illustrated in the previous sections, for each ETF, the following indices have been introduced and calculated:

- Transport type: (i) ETFs branch Optimization Index Iob, (ii) ETFs Optimization Index Iof, (iii) Sub-Network Index $I_{s}$ and (iv) Daily Accessibility Index $I_{g}$.

- Economic type: (v) Gross Domestic Product Index IOb and (vi) Employment Rate Index $I_{e}$.

Indices from (iii) to (vi have been related to index (i) as shown in figures 6 to 10. In all the elaborations it has always been seen (even if with different shades) that TF with low indices (ii-v) are often identified by TFs branches with low Optimization Index (i). This aspect indicates that a direct correlation is established between the Optimization Index (i) and the transport and socio-economic factors analysed, and therefore that the improvement of these factors depends on the improvement of multimodal transport optimization.

This aspect indicates that a direct correlation is established between the Optimization Index (i) and the transport and socio-economic factors analysed, and therefore that the improvement of these factors depends on the improvement of multimodal transport system optimization.

A second clear phenomenon emerging from the analyses shows that ETFs with both transport and economic high index values are located in the regions of central-northern Europe, except for some particular cases described in the relevant sections. This happens for all the indices, as can be seen from the previous figures, and confirms the primary role of that area in terms of transport and socio-economic development. In fact, the largest European productive activities are concentrated in this area, supported by an efficient transport system.

These behaviours and correlation are also confirmed by a further analytical step. For each ETF has been performed a crosscheck between the ETFs Optimization index IOf (ii) 
and the socio-economic indices $I_{g}$ and $I_{e}$, in order to deeply evaluate the relation between the optimization/completeness of the land transport infrastructure system and the socioeconomic indices of the ETF territories.

Each one of the socio-economic indices, $I_{g}$ and $I_{e}$, has been divided into six classes, according to the ranges shown in the relative figures, in order to unify the results into one criterion. For GDP Index $I_{g}$, the classification is shown in Fig. 9, from class $1\left(I_{g}<50 \%\right)$ to class $6\left(I_{g}>150 \%\right)$. For Employment rate Index $I_{e}$, Fig. 10 shows the classification, from class $1\left(I_{e}<50 \%\right)$ to class $6\left(I_{e}>70 \%\right)$.

The scatter chart in Fig. 11 shows on the abscissa axis the $I_{O f}$ index (from 0 to 2), and on the ordinate axis the classes of subdivision of the socio-economic indices $I_{g}$ e $I_{e}$ (from 1 to 6) and the indices trends (dotted green line and dotted purple line, respectively).

The results can be summarized as follows:

- Socio-economic indices $\left(I_{g}\right.$ and $\left.I_{e}\right)$ grow with the increase in the transportation index $I_{O f}$ (see linear trend lines of the series);

- $I_{O f}=1.4$ represents a critical value above which the socio-economic indices never fall under the third class (blue dashed area in Fig. 11). This result indicates that ETFs with an Optimization Index $I_{O f}$ higher than 1.4 have a G.D.P. that is equal or greater than $75 \%$ of the average EU G.D.P., as well as an employment rate higher than $55 \%$ of the population in working age;

- Since the trend line gradient (1.15) of $I_{g}$ index is higher than $I_{e}$ index one (0.718), we can deduce that $I_{g}$ index is more sensitive than the $I_{e}$ index to the transport index $I_{O f}$.

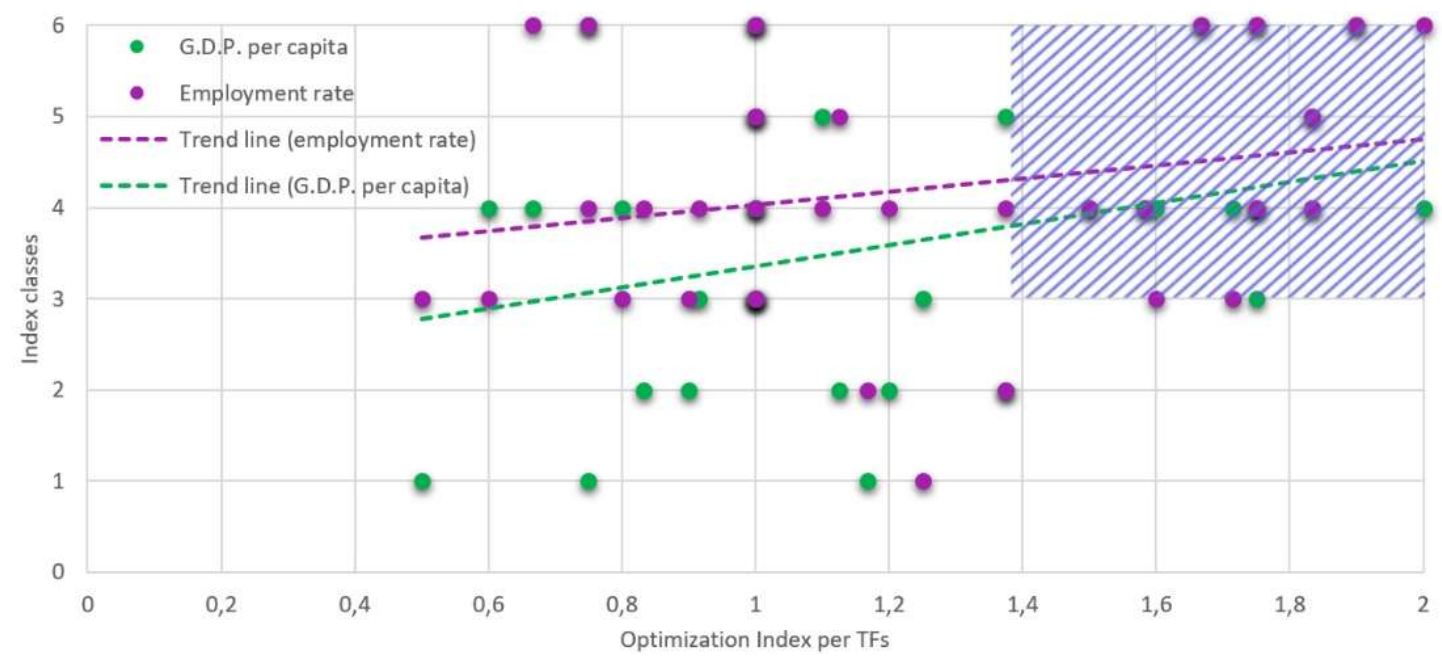

Fig. 11: Graph of the distribution of socio-economic indices values as functions of TFs optimization index.

\section{Conclusions}

In this paper has been proposed and illustrated an innovative method, Territorial Frames (TFs) model based, to analyse the relation among the main urban and productive agglomerations, the endowment and performance features of the land transport network, and the socio-economic conditions.

The proposed model allowed the European spatial context (E-28, extended to Switzerland, Norway and the Balkan area) to be divided into a multi-scalar sum of European TFs (ETFs), conceived and designed as parts of the territory, with 
homogeneous spatial and socio-economic characteristics, delimited by transportation corridors.

The ETFs components have been identified as follows:

1. Branches defined as multimodal corridors where there is the co-presence of the main road (motorways and expressways) and the electrified rail links

2. Hubs, important intersections of the branches.

3. Nodes, coinciding with the Metropolitan European Growth Areas (MEGAs), defined by the ESPON study as major European metropolitan areas of growth.

The application of the proposed method and its criteria has led to the unambiguous and reproducible construction of the spatial configuration of ETFs.

Several analyses have been carried out by means the definition of ETFs indices relating to transportation and socio-economic aspects.

The analyses results show a close correlation between above aspect .

This relation, determined in numerical terms, proves that the economical strongest European territories (north-central Europe) are largely supported by ETFs, whose network consists of well-organized urban and productive agglomerations (nodes) and high speed, accessible and integrated transport links (branches). Vice versa, the weakest territories are the most peripheral ones, which present both lower ETFs Optimization Index and lower indices of GDP and employment rate.

The results of the study have proven that the completeness of ETFs is an essential factor in the development of settlement and production systems, as it implies the optimization, and therefore the functionality, of the transport system and the efficiency of the connections to the environmental and landscape systems inside the TFs.

The next steps of the research will concern the extension of the model also to maritime transport network and the analytical insights of the ETFs role in spatial planning.

\section{References}

Albrechts, L. (2006) "Bridge the Gap: From Spatial Planning to Strategic Projects", European Planning Studies, Vol. 14, No. 10, 1488-1500.

Allmendinger, P., Haughton, G. (2009) "Soft spaces, fuzzy boundaries, and metagovernance: the new spatial planning in the Thames Gateway", Environment and Planning A, vol. 41, 617-633.

Bauman, Z. (1998) "On Glocalization: or Globalization for some, Localization for some Others", Thesis Eleven, Vol. 54, Issue 1, 37-49, Doi: https://doi.org/10.1177/0725513698054000004.

Bernardino, J. et al. (2015) "Transport demand evolution in Europe - factors of change, scenarios and challenges", Eur J Futures Res, Vol. 3 (13), Doi: http://dx.doi.org/10.1007/s40309-015-0072-y.

Brenner, N. (1999) "Globalisation as reterritorialisation: The re-scaling of urban governance in the European Union", Urban Studies, Vol. 36, No 3, 431-451.

Carmona, M. et al. (2003) Public Places - Urban Spaces. The Dimensions of Urban Design, Architectural Press, Oxford.

Choay, F. (1992) L'Orizzonte del posturbano, D’Alfonso, E. (eds), Officina Edizioni, Roma.

Davoudi, S. (2003) "Polycentricity in European Spatial Planning: From an analytical tool to a normative agenda", European Planning Studies, Vol. 11, No. 8, 979-999. 
Di Ludovico, D., D’Ascanio, F. (2019) "European cross-scale spatial planning and Territorial Frames in the Italian Median Macroregion", European Planning Studies, Vol. 27, Issue 7, 1369-1390, Doi: https://doi.org/10.1080/09654313.2019.1581729.

Di Ludovico, D., D’Ovidio, G. (2017) “Transportation Network Role for Central Italy Macroregion Development in a Territorial Frames Model Based", Materials Science and Engineering, No. 245, Doi: https://doi.org/10.1088/1757-899X/245/4/042039.

Di Ludovico, D., Properzi, P., Santarelli, A. (2014) "Median Italy: Territorial Diversity as the Cornerstone of Regional Development", Advanced Engineering Forum 11, 20 26, Doi: https://doi.org/10.4028/www.scientific.net/aef.11.20.

Di Ludovico, D., Properzi, P. (2012) "Evolution of the network of cities in the central macroregion between reconstruction and underuse2, in: Vergano, A., Caruana, A., Gateways - Smart Planning for Europe's Gateway Cities. Connecting peoples, economies and places, 1-9, INU Publisher, Roma (IT).

D’Ovidio, G., Crisi, F., Lanzara, G. (2011) "Design and Optimization of UAQ4 Experimental Maglev Module", Materials Science Forum, Vol. 1058, n. 670, 42-47, Doi: https://doi.org/10.4028/www.scientific.net/MSF.670.42.

D’Ovidio, G. et al. (2007) "Lift and Guidance Forces by Using Iron-magnetic Track with Side Rims and Passive HTC Superconducting Plate: Experimental Analyses", Journal of Materials Processing Technology, Vol. 181, Issues 1-3, 18-24, Doi: https://doi.org/10.1016/j.jmatprotec.2006.03.047.

EC (2017) Transport infrastructure: Second generation of the work plans of the 11 European Coordinators, European Commission, in: https://ec.europa.eu/transport/node/4876 (Accessed: 29.04.2020).

ESPON (2005) ESPON 111 Potentials for polycentric development in Europe, EsponNordregio, in: https://www.espon.eu/sites/default/files/attachments/fr-1.1.1 revisedfull 0.pdf (Accessed 29.04.2020).

Faludi, A. (2010a) "Centenary Paper: European Spatial Planning: Past, Present and Future", The Town Planning Review, Vol. 81, No. 1, 1-22.

Faludi, A. (2010b) Cohesion, Coherence, Cooperation: European Spatial Planning Coming of Age?, Routledge, London and New York.

Fiorello, D., Nökel, K., Martino, A. (2018) "The TRIMODE integrated model for Europe", Transportation Research Procedia, Vol. 31, 88-98. Doi: http://dx.doi.org/10.1016/j.trpro.2018.09.048.

Hall, P. (2001) "Urban Development and Research Needs in Europe", Cerum, Report n. 8 , Umeå, Sweden.

Jones, H., Moura, F., Domingos, T. (2014) "Transport infrastructure project evaluation using cost-benefit Analysis", Procedia - Social and Behavioral Sciences, Vol. 111, 400-409, Doi: http://dx.doi.org/10.1016/j.sbspro.2014.01.073.

Lundqvist, L., Mattsson, L.G. (2002) "National Transport Models: Introduction and Comparative Analysis", in: Lundqvist. L., Mattsson. L.G. (eds), National Transport Models. Advances in Spatial Science, Springer, Berlin, Heidelberg.

Noguera, J. et al. (2017) PROFECY - Processes, Features and Cycles of Inner Peripheries in Europe, ESPON EGTC, in: https://www.espon.eu/inner-peripheries (Accessed 09.03.2020).

Raines, T., Goodwin, M., Cutts, D. (2017) The Future of Europe, Comparing Public and Elite Attitudes, The Royal Institute of International Affairs. London, in: https://www.chathamhouse.org/sites/files/chathamhouse/publications/research/201706-20-future-europe-attitudes-raines-goodwin-cutts-final.pdf (Accessed 29.04.2020). 
Rauhut, D. (2016) Polycentricity: A Critical Discussion, Draft paper prepared for the 56th Congress of the European Regional Science Association, 23-26 August 2016, Vienna, Austria.

Robertson, R. (1992) Globalization: Social Theory and Global Culture. Sage publications. London-Thousand Oaks-New Dehli.

Saeedi, H. et al. (2017) "European intermodal freight transport network: Market structure analysis", Journal of Transport Geography, Vol. 60, 141-154. Doi: http://dx.doi.org/10.1016/j.jtrangeo.2017.03.002.

Shaw, D., Sykes, O. (2004) "The concept of polycentricity in European spatial planning: reflections on its interpretation and application in the practice of spatial planning", International Planning Studies, Vol. 9, Issue 4, 283-306.

Tranus (2011) TRANUS: Integrated Land Use and Transport Modeling System, in: http://www.tranus.com/tranus-english/download-install (Accessed 09.02.2021).

UN-DESA (2014) World Urbanization Prospects, revision 2014, in: http://www.un.org/en/development/desa/publications/2014-revision-worldurbanization-prospects.html (Accessed 29.04.2020).

UNECE (2017) Trans-European Railway High-Speed Master Plan Study, in: https://www.unece.org/fileadmin/DAM/trans/main/ter/terdocs/TER_HighSpeed Master_Plan Study.pdf (Accessed 21.03.2020).

Van Meeteren, M. et al. (2015) "Pacifying Babel's Tower: A scientometric analysis of polycentricity in urban research", Urban Studies, Vol. 53, Issue 6, 1278-1298, Doi: http://dx.doi.org/10.1177/0042098015573455.

Waterhout, B. (2002) "Polycentric development: what is behind it?", in: Faludi, A. (eds) European Spatial Planning, Cambridge, MA: Lincoln Institute of Land Policy, 83-103.

Williams, R.H. (1996) European Union spatial policy and planning, Paul Chapman Publishing, London. 